Eur J Clin Chem Clin Biochem

1995; 33:23-29

(c) 1995 Walter de Gruyter \& Co.

Berlin - New York

\title{
A Method for the Simultaneous Determination of Creatinine and Uric Acid in Serum by High-Performance-Liquid-Chromatography Evaluated Versus Reference Methods
}

\author{
By R. Kock, S. Seitz, B. Delvoux and H. Greiling \\ Institute of Clinical Chemistry and Pathobiochemistry, Medical Faculty, University of Technology Aachen, \\ Aachen, Germany
}

(Received February 14/September 20, 1994)

Summary: A high performance liquid chromatography (HPLC) with isocratic ion-pair-reversed-phase separation and simultaneous UV-detection at $232 \mathrm{~nm}$ and $292 \mathrm{~nm}$ is proposed as a method for the simultaneous determination of uric acid and cratinine in serum. The only sample preparation required is an appropriate dilution with the eluent and membrane filtration on non-adsorbent $0.2 \mu \mathrm{m}$ membrane-filtration-devices.

The inaccuracy of the method has been determined for NIST-SRM-909 $(n=10)$ and was $+0.5 \%$ for creatinine as well as for uric acid. The imprecision in this case was $0.8 \%$ for both analytes. The within-run imprecision for creatinine/uric acid was $0.4-0.5 \% / 0.2-0.4 \%$ in the case of standards and $0.6-0.8 \% / 0.4-0.7 \%$ in the case of serum-pools. The between-run imprecision for creatinine/uric acid obtained from serum pools was $0.8-1.1 \% /$ $0.7-1.0 \%$.

The results for creatinine have been compared to those from an isotope dilution-gas chromatography-mass spectrometry using $\left[{ }^{13} \mathrm{C},{ }^{15} \mathrm{~N}_{2}\right]$ creatinine as internal standard and selected mass detection at $\mathrm{m} / \mathrm{e}=329$ and $\mathrm{m} / \mathrm{e}=332$. The results for uric acid have been compared to an HPLC-method published previously (Kock R et al. J Clin Chem Clin Biochem 1989; 27:157-62). The method comparisons $(n=55)$ for the new combined method presented versus the reference method for creatinine and the candidate reference method for uric acid resulted in coefficients of correlation of $r=1.000$ for both analytes.

The new combined method presented is useful for the analysis of patient samples where the classical photometric procedures do not give reliable results, as often observed in monitoring after transplantation surgery. The method presented here is an alternative to less specific photometric procedures with poorer reproducibility previously used in such cases.

\section{Introduction}

Creatinine and uric acid are two of the most often measured clinical-chemical analytes. For the determination of creatinine, the unspecific Jaffé-method (2), although subject to perturbation by many interfering substances from endogenous and exogenous origin, has remained popular. More specific enzymatic determination methods for creatinine have been developed $(3-4)$, but due to the complexity of their reaction pathways they are not free of interferences. The determination of uric acid in serum is much less sensitive to interferences than the determination of creatinine.

The aim of this study was to develop a combined method for the determination of both creatinine and uric acid, based on high performance liquid chromatography, which should be as matrix independent as possible, imprecision and inaccuracy should be below $1 \%$ and the method should be suitable for patient samples. When 
photometric methods do not yield plausible results or when creatinine monitoring is critical - for example in transplantation surgery - the use of a HPLC method is justified instead of photometric methods (i. e. Jaffe's method) after adsorption to Fuller's earth or the determination of a sample blank after enzymatic creatinine-degradation are performed (5). In order to test inaccuracy, NIST-SRM-909 human serum control material was used, additionally method comparisons were performed with $n=5$ pooled serum specimens and $n=50$ individual serums specimens. As a comparison method for creatinine a reference method, an isotope dilution-gas chromatography-mass spectrometry (ID-GC-MS) with $\left[{ }^{13} \mathrm{C},{ }^{15} \mathrm{~N}_{2}\right]$ creatinine as internal standard was used, for uric acid a candidate reference HPLC method (1) was choosen.

\section{Materials and Methods}

Chemicals

The uric acid (purity $99.7 \% \pm 0.1 \%$ ) and creatinine (purity $99.8 \%$ $\pm 0.1 \%$ ) used for preparation of the standard solutions were Standard Reference Materials (SRM913 resp. SRM914a) from the National Institute of Standards and Technology, Washington D.C. 20234, U. S.), $\left[{ }^{13} \mathrm{C},{ }^{15} \mathrm{C}_{2}\right]$ creatinine used as internal standard in IDGC-MS-measurements was a generous gift of Dr. Kobold, Boehringer Mannheim GmbH, Werk Tutzing, N-Methyl-N-trimethylsilyltrifluoroacetamide as well as pyridine (Silylation Grade Solvent) was supplied by Macherey \& Nagel (Düren, Germany), creatinine-imidohydrolase and uricase were from Boehringer Mannheim (Mannheim, Germany), all other chemicals were of analytical grade and purchased from Merck (Darmstadt, Germany), SIGMA (Munich, Germany) and from Baker (Groß-Gerau, Germany). Bakerbond SPE-solid phase extraction cartridges were from Baker (Groß-Gerau, Germany). Deionized water was prepared with a Milli-Q apparatus (Millipore GmbH, Eschborn, Germany).

\section{Samples}

The control material used for checking inaccuracy of the methods was Human Serum SRM 909 from the National Institute of Standards and Technology, Washington D.C. 20234, U. S.). The other control materials were Precinorm U (Chargen-Nr. 16915101) and Precipath U (Chargen-Nr. 16913801) from Boehringer Mannheim GmbH (Mannheim, Germany).

For the recovery experiments 5 pools were prepared from patient sera. For the method comparisons 50 patient samples, 20 in the normal range and 30 in the pathological range, were used. All specimens were collected in Sarstedt-Monovettes with separation-gel. After centrifugation serum was obtained.

\section{Instruments and settings}

\section{New' combined high performance liquid chromatography}

The HPLC was performed on a Bruker LC-21 chromatographic system with a LC-51 autoinjector and a tuneable Gynkotec 4-wavelength detector Model tuned at $232 \mathrm{~nm}$ for the detection of creatinine and $292 \mathrm{~nm}$ for the detection of uric acid. System controlling, data acquisition, integration and calibration was performed with Bruker Chromstar V3.20, the absorbance data at $232 \mathrm{~nm}$ and 292 $\mathrm{nm}$ were acquired simultaneously.
For the candidate HPLC-method for uric acid the chromatographic conditions were as described in l.c. (1), for the new combined HPLC-method presented here, the simultaneous determination of uric acid and creatinine, a $\mu$ Bondapak $\mathrm{C} 18$ (10 $\mu \mathrm{m}$ particle-size), $300 \mathrm{~mm} \times 3.9 \mathrm{~mm}$ analytical column (Waters Chromatographie, Eschborn, Germany) with $\mu$ Bondapak $\mathrm{C} 18$ precolumn insert was used. The eluent buffer $A$ consisted of $27.5 \mathrm{mmol} / 1$ sodium dihydrogenphosphate, $2.5 \mathrm{mmol} / \mathrm{l}$ octanesulphónic acid, $\mathrm{pH} \mathrm{4.2,} \mathrm{aceto-}$ nitrile, volume fraction 0.1 , column purging was performed with eluent buffer $B$ consisting of $2.5 \mathrm{mmol} / \mathrm{l}$ sodium dihydrogenphosphate, $2.5 \mathrm{mmol} / 1$ octanesulphonic acid, acetonitrile, volume fractions 0.60 . The $\mathrm{pH}$ of buffer $\mathrm{B}$ was set to 4.2 by adding concentrated $\mathrm{NaOH}$. The flow-rate was $1 \mathrm{ml} / \mathrm{min}$. The injection volume was $50 \mu \mathrm{l}$ for all samples. The duration of one chromatography was $8 \mathrm{~min}$. Every 15 chromatographies the column was purged with Buffer $B$ for 5 min and the column was then equilibrated with Buffer $\mathrm{A}$ for $35 \mathrm{~min}$.

\section{Candidate reference high performance liquid chromatography for uric acid}

The candidate reference HPLC was performed identically as described before (1).

Isotope dilution-gas chromatography-mass spectrometry of creatinine

The instrument used was a Finnigan 1020 combined gas-chromatograph quadrupole-mass-spectrometer with Perkin-Elmer Sigma 3 gas-chromatograph, equipped with a Permabond FS-SE-52, 0.25 $\mu \mathrm{m}, 25 \mathrm{~m} \times 0.32 \mathrm{~mm}$ ID capillary column (Macherey \& Nagel, Düren, Germany).

GD-conditions: The carrier gas was helium at $70 \mathrm{kPa}$ inlet pressure, the split-exit was set at $30 \mathrm{ml} / \mathrm{min}$, the injector temperature was $190^{\circ} \mathrm{C}$, the oven temperature was isothermal $170^{\circ} \mathrm{C}$, the transfer line has heated to $190^{\circ} \mathrm{C}$. The retention-time of the creatininederivative was $3.5 \mathrm{~min}$.

MS-conditions: EI-Modus $(70 \mathrm{eV})$, selected mass detection at $\mathrm{m} / \mathrm{e}$ $=329 \pm 0.25$ (creatinine) and $\mathrm{m} / \mathrm{e}=332 \pm 0.25\left(\left[{ }^{13} \mathrm{C},{ }^{15} \mathrm{C}_{2}\right]\right.$ creatinine), 0.28 seconds per scan and 0.14 seconds scantime per mass.

\section{Procedures and measurements}

\section{Weighing procedures}

Uric acid (SRM 913), creatinine (SRM 914) and the isotopically labelled creatinine were weighed on a micro balance (Mikrowaage 708501, Fa. Sartorius, Göttingen, Germany). All other weighing procedures, including all required calibrations of volumetric devices, were done on a semimicro balance (Halbmikrowaage 2004 MP, Fa. Sartorius, Göttingen, Germany).

\section{Preparation of stock standards and reconstitution of control sera}

The reconstitution of lyophilized control sera as well as the preparation of the uric acid standards was performed as previously described (1), giving a stock standard concentration for uric acid of $357 \mu \mathrm{mol} / \mathrm{l}$. The uric acid stock standard was freshly prepared every day. Creatinine stock-standards were prepared by dissolving the weighed SRM $914-2.3 \mathrm{mg}$ for HPLC, $1.5 \mathrm{mg}$ for ID-GC-MS - in $100 \mathrm{ml}$, giving a stock standard concentration for creatinine of $203 \mu \mathrm{mol} / 1$ for HPLC-measurements and a stock standard concentration for creatinine of $133 \mu \mathrm{mol} / \mathrm{l}$ for ID-GC-MS-measurements. The creatinine stock standard was stable for at least one week at $4^{\circ} \mathrm{C}$. As internal standard for the ID-GC-MS $3 \mathrm{mg}$ of the isotopically labelled creatinine were dissolved in $25 \mathrm{ml}$ HPLC-water, giving a stock standard concentration for the internal standard of 1061 $\mu \mathrm{mol} / \mathrm{l}$. This internal standard was prepared once, and aliquots of $1 \mathrm{ml}$ were freezed at $-70^{\circ} \mathrm{C}$. 


\section{Serum dilutions}

All sera, control sera, patient sera and serum pools were diluted with a gravimetrically calibrated Microlab 1000 (Fa. Hamilton, Darmstadt, Germany). The diluted serum samples were filtered through membrane filtration devices with a pore diameter of 0.2 $\mu \mathrm{m}$ (Sartorius GmbH, Göttingen, Germany).

\section{Measurements with the new combined HPLC}

For the new combined HPLC-method presented here, the standards used for calibration contained both analytes. The calibration standards were prepared freshly every day with the Microlab 1000 system. Equal amounts of the stock standard solutions of creatinine and uric acid were mixed and diluted with elution buffer $A$ to give standards with $0.05 \mathrm{c}_{\text {stock }}, 0.1 \mathrm{c}_{\text {stock }}$, and $0.15 \mathrm{c}_{\text {stock }}$ for creatinine as well as uric acid, giving the following final concentrations (in $\mu \mathrm{mol} / \mathrm{l}$ ) for uric acid/creatinine: $53.4 / 30.45,35.6 / 20.3,17.8 / 10.15$. The calibration range was therefore $17.8-53.4 \mu \mathrm{mol} / \mathrm{l}$ for uric acid and $10.15-30.45 \mu \mathrm{mol} / 1$ for creatinine. For all serum samples the dilution $1: 10$ was measured first. Measurements with an area response out of the calibrated concentration-range were rechromatographed in an appropriate second dilution which in our study for the most cases was a dilution of $1: 20$. Only 7 sera with creatinine concentration above $600 \mu \mathrm{mol} / 1$ required a $1: 30$ dilution for the determination of creatinine, in the case of serum concentrations below $50 \mu \mathrm{mol} / 1$ and/or uric acid serum concentrations below 178 $\mu \mathrm{mol} / \mathrm{l}$ the serum dilution 1:5 was chromatographed. All serum, SRM 909 and standard samples were prepared twice. The measuring sequence in this study was as follows: low standard in triplicate, medium standard in triplicate, high standard in triplicate, SRM 909 in triplicate, 5 serum samples in triplicate, SRM 909 in triplicate, 5 serum samples in triplicate. Then in the second run the procedure was repeated with the second dilution of all standards, the SRM 909 and the 10 sera.

\section{Calibration and calculation for the new combined HPLC}

For the new method, the calibrations for creatinine as well as uric acid were based on peak areas; linear concentration peak-area-relationships were used for both analytes, whereby the calibration curves showed neither an intercept significantly deviating from the origin nor a significant non-linearity.

\section{Measurements with the candidate reference HPLC for uric acid}

All serum samples were treated in this case like the reconstituted control sera in that study (1).

\section{Calibration and calculation for the candidate reference HPLC for} uric acid

For the candidate reference HPLC for uric acid, a calibration method previously published (1) was used.

\section{Measurements with the ID-GC-MS for creatinine}

Internal standard $(50 \mu \mathrm{l})$ were added to $300 \mu \mathrm{l}$ (Standard A), 400 $\mu \mathrm{l}$ (Standard B), $500 \mu \mathrm{l}$ (Standard C) creatinine-stock-standard with a Microlab 1000 (Hamilton, Darmstadt, Germany), HPLC-water was added to give a final volume of $1 \mathrm{ml}$, then the standards were evaporated at $60^{\circ} \mathrm{C}$ under a stream of nitrogen to dryness. For the determination of the isotope-ratio of the unlabelled standard and the labelled internal standard, $400 \mu \mathrm{l}$ of the stock standard or $50 \mu \mathrm{l}$ of the internal standard (both containing about $6 \mu \mathrm{g}$ creatinine) were were evaporated directly. Fifty $\mu l$ of $1: 1(v: v)$ mixture of $N$ methyl-N-trimethylsilyltrifluoracetamide and pyridine (dried over molecular sieve) was added to the dried residue and the derivatisation was performed for $40 \mathrm{~min}$ at $60^{\circ} \mathrm{C}$.
For the first pipetting step, it is necessary to fit individually the aliquot of each serum sample to a constant amount of internal standard to give an isotope ratio (unlabelled/labelled) in the final IDGC-MS measurement between 0.9 and 1.1. Therefore $50 \mu l$ of the internal standard were added to an anliquot of serum (typically between 100-600 $\mu \mathrm{l}$ ), which contained about $6 \mu \mathrm{g}$ creatinine. This is the most critical volumetry in the ID-GC-MS procedure and has to be performed very exactly. Then $0.1 \mathrm{~mol} / \mathrm{l} \mathrm{HCl}$ with an amount of half of the volume of the serum aliquot was added and finally HPLC-water was added to give a final volume of $1 \mathrm{ml}$. This sample was mixed and equilibrated for $2 \mathrm{~h}$. Next a solid-phase extraction of the sample was performed on Bakerbond SPE-columns, which were previously conditioned with $3 \mathrm{ml}$ methanol and $3 \mathrm{ml}$ HPLCwater. After washing the column with $3 \mathrm{ml}$ water, the creatinine was extracted from the columns with $4 \mathrm{ml}$ eluent-buffer $(6.5 \mathrm{mmol} /$ $1 \mathrm{Na}_{2} \mathrm{HPO}_{4}, 2.5 \mathrm{mmol} / \mathrm{l} \mathrm{NaH} \mathrm{PO}_{4}, 150 \mathrm{mmol} / \mathrm{l} \mathrm{NH} \mathrm{CO}_{3}, \mathrm{pH} 8.0$ ), the first $2 \mathrm{ml}$ of the column-eluate was discarded. The $2 \mathrm{ml}$ eluate was evaporated under a nitrogen-stream at $60^{\circ} \mathrm{C}$ to dryness, the residue was further processed as described for the evaporated standard samples. From each standard, control serum and patient serum, two samples were prepared for ID-GC-MS and each sample was chromatographed in triplicate.

Calibration and calculation for the candidate reference HPLC for uric acid

For the GC-MS measurements $1.5 \mu$ were injected, and peak-integration was performed with the Finnigan-1020 Software. Subsequent calculations were performed using the procedure described by Siekmann (6).

\section{Results}

\section{Specificity}

The chromatogram of a uric acid/creatinine-standard is shown in figure $1 \mathrm{a}$, the chromatogram of a control serum is shown in figure $1 \mathrm{~b}$ and that of a patient serum sample in figure 1c. For the patient serum a much more complicated matrix compared to the control material is evident in the chromatogram at $232 \mathrm{~nm}$. After enzymatic treatment with creatinine-imidohydrolase and uricase interfering substances underlying the peaks of the analytes could not be detected in the samples used in this study.

\section{Imprecision}

The imprecision of the chromatographic method and the applied peak integration procedure was determined from the areas obtained for the triplicate measurements of the samples. This imprecision was less than $0.2 \%$ for the standards, less than $0.3 \%$ for SRM 909 and less thän $0.6 \%$ for the serum samples. The deviations between two different dilutions never exceeded $0.4 \%$ for all samples measured in this study.

The within-run imprecision has been calculated for the means of the triplicates of three standard samples and five serum-pools from $n=10$ runs and was for both analytes less or equal than $0.5 \%(\mathrm{CV})$ in the case of standards and less or equal than $0.8 \%(\mathrm{CV})$ in the case of pool sera (tab. 1a). The day-to-day imprecision has 

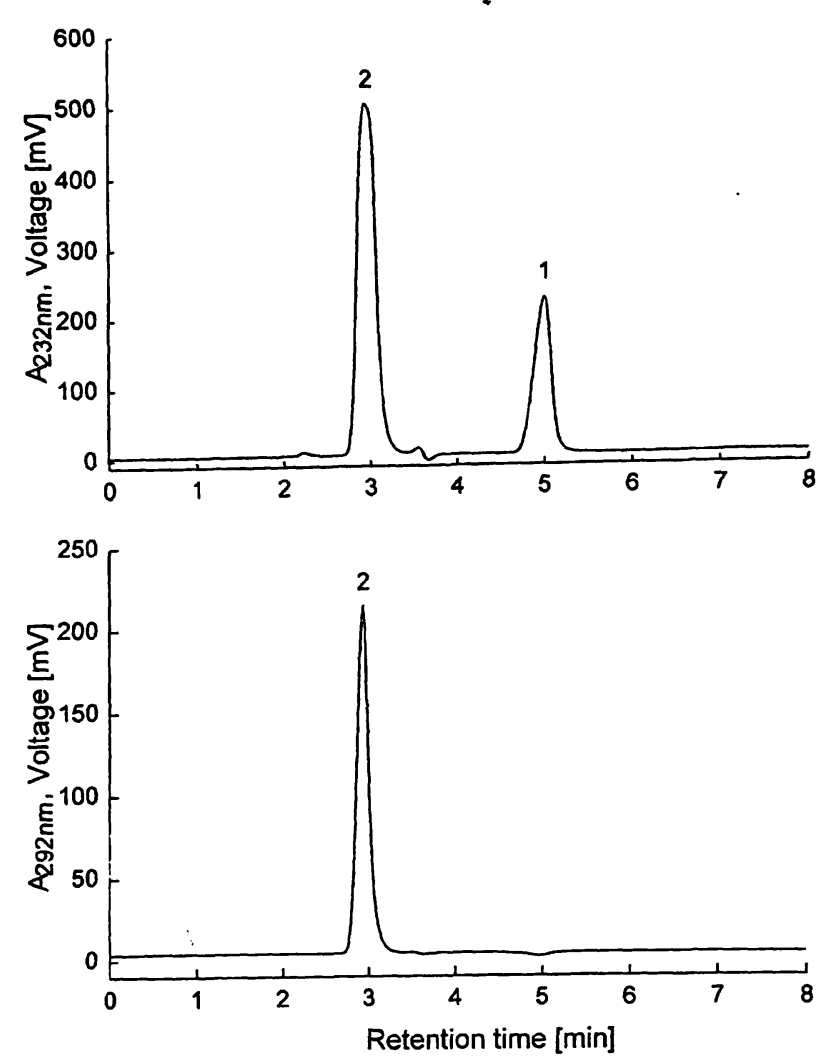

Fig. 1a Chromatogram obtained with the new combined HPLC method for a standard mixture of $1 \mathrm{nmol}$ creatinine and $1.8 \mathrm{nmol}$ uric acid performed with UV absorbance detection at $232 \mathrm{~nm}$ and $292 \mathrm{~nm}$.

Peak identification: 1 . creatinine; 2 . uric acid

Tab. 1a Within-run imprecision for the method for the simultaneous determination of uric acid and creatinine, calculated for three aqueous standards and five human pool sera from $n=10$ runs. For the determination of creatinine Standard 1 and Pool 1 were measured in a $1: 5$ dilution, Standard 2 and Pool 2-4 were measured in a $1: 10$ dilution, Standard 3 and Pool 5 were measured in a $1: 20$ dilution.

For the determination of uric acid, Standard 1-2 and Pool 1-4 were measured in a $1: 10$ dilution, Standard 3 and Pool 5 were measured in a $1: 20$ dilution.

\begin{tabular}{|c|c|c|c|c|c|c|c|c|}
\hline & \multicolumn{8}{|c|}{ Creatinine in $\mu \mathrm{mol} / \mathrm{l}$} \\
\hline & \multicolumn{3}{|c|}{ Standard } & \multicolumn{5}{|l|}{ Pool } \\
\hline & 1 & 2 & 3 & 1 & 2 & 3 & 4 & 5 \\
\hline $\bar{x}$ & 100.0 & 200.0 & 299.8 & 62.5 & 109.7 & 153.1 & 182.8 & 400.4 \\
\hline $\pm s$ & 0.5 & 0.7 & 1.6 & 0.5 & 0.8 & 0.9 & 1.3 & 3.4 \\
\hline \multirow[t]{4}{*}{$\mathrm{CV}(\%)$} & 0.5 & 0.4 & 0.5 & 0.8 & 0.7 & 0.6 & 0.7 & 0.8 \\
\hline & \multicolumn{8}{|c|}{ Uric acid in $\mu \mathrm{mol} / \mathrm{l}$} \\
\hline & \multicolumn{3}{|c|}{ Standard } & \multicolumn{5}{|l|}{ Pool } \\
\hline & 1 & 2 & 3 & 1 & 2 & 3 & 4 & 5 \\
\hline $\begin{array}{l}\bar{x} \\
\pm s\end{array}$ & 198.8 & 498.3 & 800.3 & 243.7 & 420.7 & 483.6 & 338.8 & 736.8 \\
\hline $\pm s$ & 0.8 & 1.5 & 1.7 & 1.8 & 2.7 & 2.4 & 1.3 & 4.4 \\
\hline CV $(\%)$ & 0.4 & 0.3 & 0.2 & 0.7 & 0.6 & 0.5 & 0.4 & 0.6 \\
\hline
\end{tabular}

$\mathrm{CV}=$ Coefficient of variation in $\%$
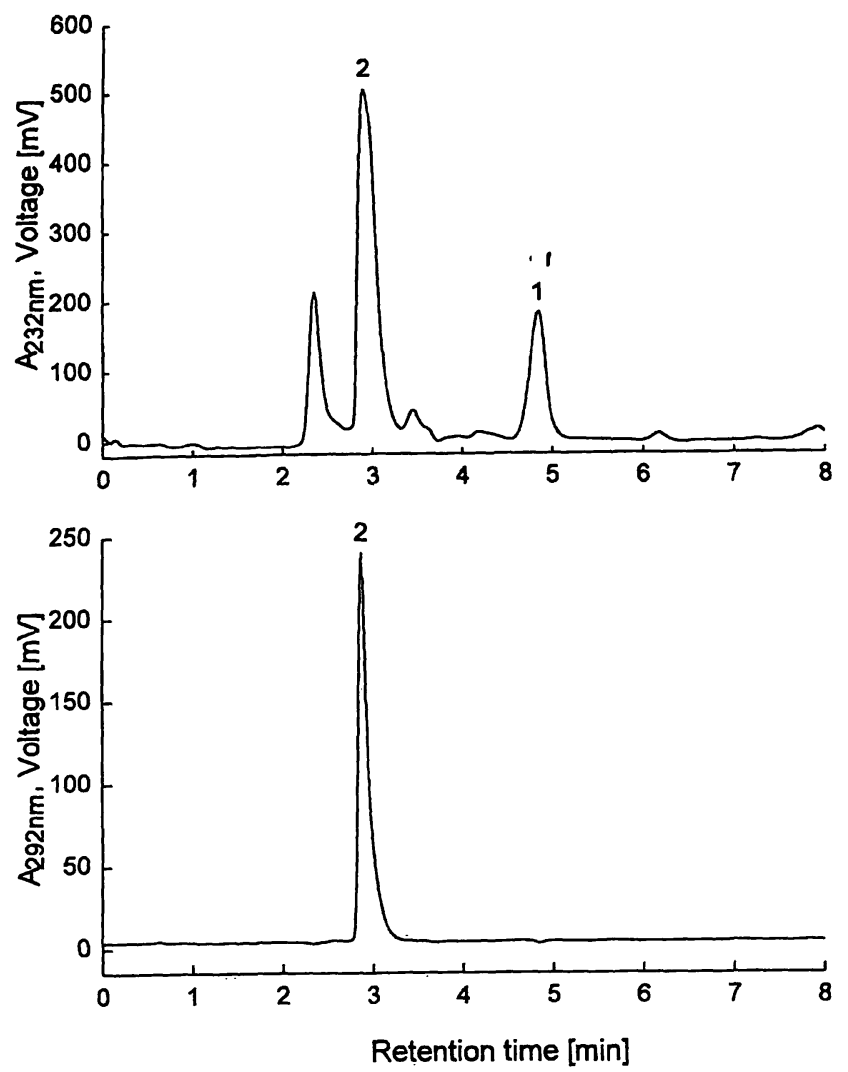

Fig. 1b Chromatogram obtained with the new combined HPLC method for a sample of a control serum (SRM 909), performed with UV absorbance detection of $232 \mathrm{~nm}$ and $292 \mathrm{~nm}$. Injected were $50 \mu \mathrm{l}$ of a $1: 10$ diluted serum sample, giving an amount of $0.75 \mathrm{nmol}$ creatinine and $2.4 \mathrm{nmol}$ uric acid.

Peak identification: 1 . creatinine; 2 . uric acid

been calculated for aliquots of the five serum-pools at $\mathrm{n}=10$ different days; the aliquots of the pools have been stored at $-70^{\circ} \mathrm{C}$ and were equilibrated at room temperature before processing after thawing. Only the pool-sera in the normal-range (Pool 1 and 2) show a CV of $1.1 \%$ in the case of creatinine, all other imprecisions determined for both analytes were less or equal than $1.0 \%$ (tab. 1b). Table 2 shows the imprecisions for the same serum pools obtained for creatinine by ID-GC-MS.

\section{Inaccuracy}

Table 3 shows the recoveries. of added uric acid and creatinine standards to a pool serum. Only in one case for the creatinine determination was the deviation $-0.7 \%$ with an $\mathrm{CV}$ of $0.5 \%$, for all other recoveries the deviations from $100 \%$ were less than the CV for both analytes. For the determination of creatinine by ID-GCMS all recoveries determined had a deviation from $100 \%$ less than the $\mathrm{CV}$.

The inaccuracy of the HPLC-method for the simultaneous determination of uric acid and creatinine was checked with the control material.SRM-909. The coefficient of variation for this control material, obtained from 

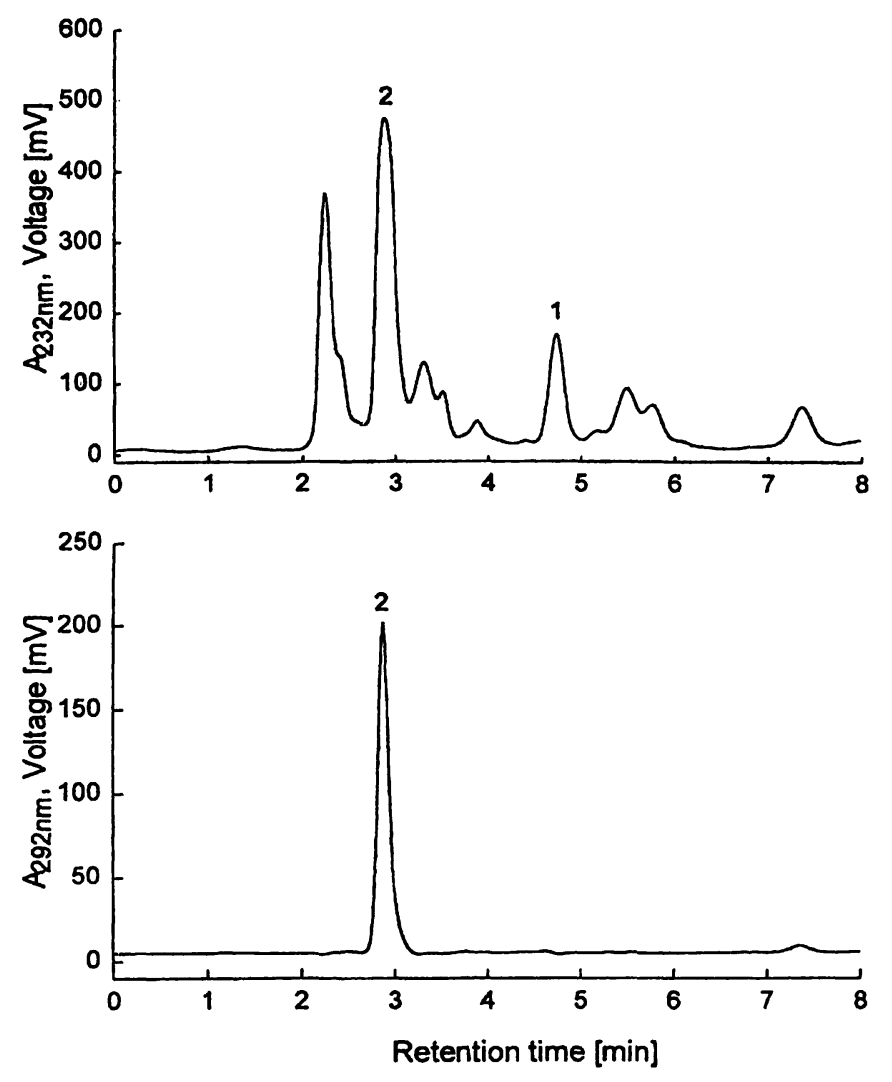

Fig. 1c Chromatogram obtained with the new combined HPLC method for a sample of a patient serum, performed with UV absorbance detection at $232 \mathrm{~nm}$ and $292 \mathrm{~nm}$. Injected were $50 \mu \mathrm{l}$ of a $1: 10$ diluted serum sample, giving an amount of $0.6 \mathrm{nmol}$ creatinine and $2.0 \mathrm{nmol}$ uric acid.

Peak identification: 1 . creatinine; 2 . uric acid

Tab. 1b Day to day imprecision for the method for the simultaneous determination of uric acid and creatinine, calculated for five human pool sera from $n=10$ runs.

For the determination of creatinine, Pool 1 was measured in a $1: 5$ dilution, Pool 2-4 were measured in a $1: 10$ dilution, Pool 5 was measured in a $1: 20$ dilution.

For the determination of uric acid, Pool 1-4 were measured in a $1: 10$ dilution, Pool 5 was measured in a $1: 20$ dilution.

\begin{tabular}{lrrrrr}
\hline \multicolumn{7}{c}{ Creatinine in $\mu \mathrm{mol} / 1$} \\
\cline { 2 - 6 } & Pool 1 & \multicolumn{1}{l}{ 2 } & \multicolumn{1}{l}{3} & \multicolumn{1}{c}{4} & \multicolumn{1}{c}{5} \\
\hline$\overline{\mathrm{x}}$ & 61.3 & 108.7 & 152.8 & 181.7 & 396.3 \\
$\pm \mathrm{s}$ & 0.7 & 1.2 & 1.2 & 1.5 & 3.7 \\
$\mathrm{CV}(\%)$ & 1.1 & 1.1 & 0.8 & 0.8 & 0.9 \\
\hline
\end{tabular}

\begin{tabular}{lrrrrr}
\multicolumn{5}{c}{ Uric acid in $\mu \mathrm{mol} / 1$} \\
\cline { 2 - 6 } & Pool 1 & \multicolumn{1}{c}{2} & \multicolumn{1}{l}{3} & \multicolumn{1}{l}{4} & \multicolumn{1}{c}{5} \\
\hline$\overline{\mathrm{x}} \pm \mathrm{s}$ & 245.0 & 421.8 & 482.3 & 340.3 & 734.2 \\
& 1.4 & 3.2 & 3.7 & 2.5 & 4.9 \\
$\mathrm{CV}(\%)$ & 1.0 & 0.8 & 0.8 & 0.7 & 0.7 \\
\hline
\end{tabular}

$\mathrm{CV}=$ Coefficient of variation in $\%$

$\mathrm{n}=10$ determinations (performed on separate days), was $0.8 \%$ for creatinine as well as for uric acid, for both
Tab. 2 Day to day imprecision of the ID-GC-MS-method for the determination of creatinine, calculated for five human pool sera from $n=10$ runs.

For the determination of creatinine, Pool 1 was measured in a $1: 5$ dilution, Pool 2-4 were measured in a $1: 10$ dilution, Pool 5 was measured in a $1: 20$ dilution.

\begin{tabular}{lrrrrr}
\hline \multicolumn{7}{c}{ Creatinine in $\mu \mathrm{mol} / 1$} \\
\cline { 2 - 6 } & Pool 1 & \multicolumn{1}{c}{2} & 3 & \multicolumn{1}{c}{4} & \multicolumn{1}{c}{5} \\
\hline $\mathrm{x}$ & 59.5 & 110.2 & 151.6 & 182.4 & 399.3 \\
$\pm \mathrm{s}$ & 0.6 & 1.0 & 0.9 & 1.7 & 2.8 \\
$\mathrm{CV}(\%)$ & 1.0 & 0.9 & 0.6 & 0.9 & 0.7 \\
\hline
\end{tabular}

Tab. 3 Recovery of the method for the simultaneous determination of creatinine and uric acid, calculated for Pool 1, spiked with uric acid or creatinine-standard.

For creatinine, the serum samples spiked with 50.04-200.14 $\mu \mathrm{mol} / \mathrm{l}$ were measured in a $1: 10$ dilution, the sample spiked with $300.17 \mu \mathrm{mol} / \mathrm{l}$ was measured in a $1: 20$ dilution.

For uric acid, the serum samples spiked with 100.03-200.06 $\mu \mathrm{mol} / 1$ were measured in a $1: 10$ dilution, the samples spiked with $400.12-600.18 \mu \mathrm{mol} / 1$ were measured in a $1: 20$ dilution.

\begin{tabular}{llll}
\hline $\begin{array}{l}\text { Addition of } \\
\text { creatinine } \\
{[\mu \mathrm{mol} / 1]}\end{array}$ & Recovery & $\begin{array}{l}\text { Addition of } \\
\text { uric acid } \\
{[\mu \mathrm{mol} / /]}\end{array}$ & \multicolumn{1}{l}{ Recovery } \\
\hline 50.04 & $100.1 \pm 0.7$ & 100.03 & $100.4 \pm 0.7$ \\
100.07 & $99.5 \pm 0.7$ & 200.06 & $100.2 \pm 0.8$ \\
200.14 & $99.3 \pm 0.5$ & 400.12 & $99.8 \pm 0.6$ \\
300.21 & $100.4 \pm 0.8$ & 600.18 & $100.6 \pm 0.7$ \\
\hline
\end{tabular}

analytes the mean value from these $\mathrm{n}=10$ determinations deviated $+0.5 \%$ from the certified value.

For the method comparison the mean values $(n=6)$ for the serum samples were used, obtained from the two dilutions or ID-GC-MS sample preparations, each chromatographed in triplicate. For the 5 pool sera and 50 patient samples, the mean results for the method presented here were compared to the mean results of the candidate reference HPLC-method for the determination of uric acid (fig. 2a) and the reference ID-GC-MSmethod for the determination of creatinine (fig. 2b). The method comparison with the procedure of Bablok and Passing yielded the following relationships:

For uric acid (concentration range of the reference method $143 \mu \mathrm{mol} / 1-1339 \mu \mathrm{mol} / \mathrm{l}$ ) $\mathrm{C}_{\text {uric acid (combined }}$ method) $=1.002 \times \mathrm{C}_{\text {uric acid (reference HPLC) }}-0.356 \mu \mathrm{mol} / 1$ confidence interval

for slope $b: \quad 0.989 \quad-\quad 1.015$ confidence interval

for intercept a: $\quad-4.29 \mu \mathrm{mol} / \mathrm{l}-\quad+4.22 \mu \mathrm{mol} / \mathrm{l}$ coefficient of

correlation $\mathrm{r}$ :

For creatinine (concentration range of the reference 


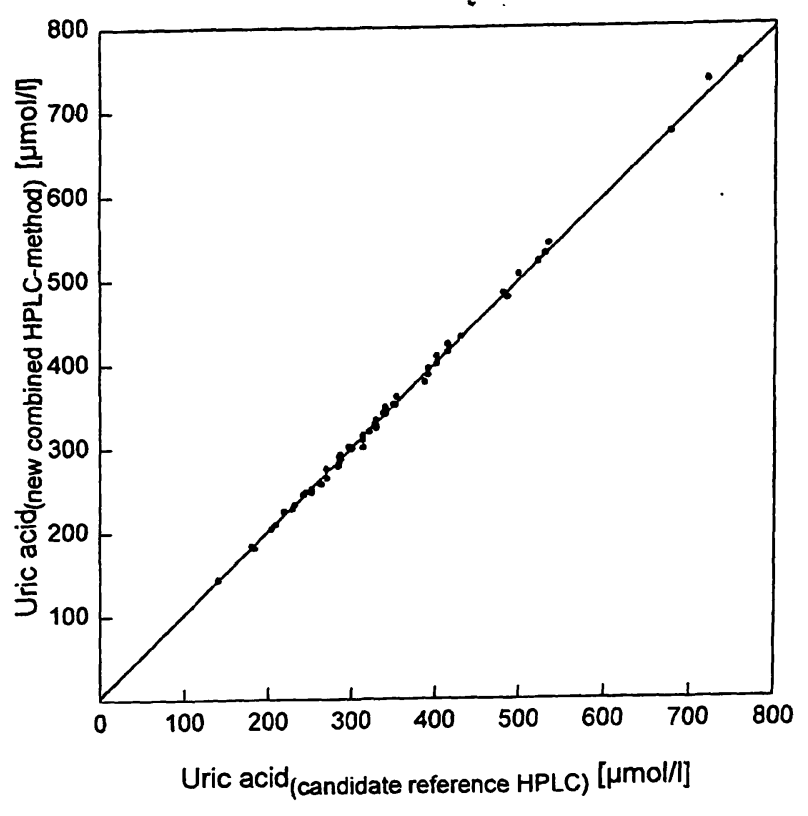

Fig. 2a Correlation of the analytical results for the means of the uric acid determination in $n=55$ serum samples with the new combined HPLC method and the candidate reference HPLC method.

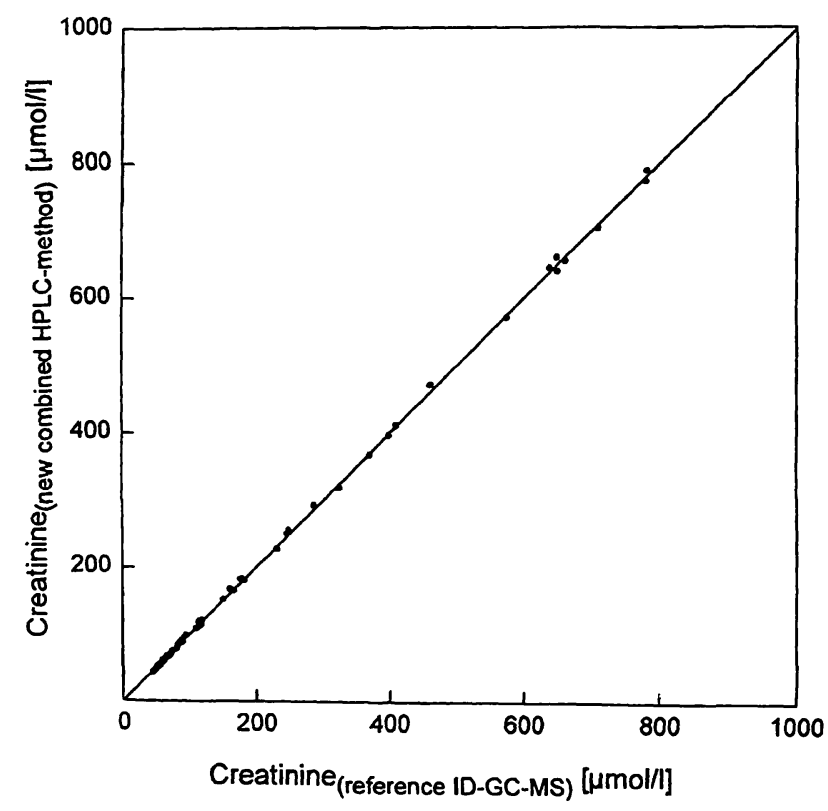

Fig. 2b Correlation of the analytical results for the means of creatinine determination in $n=55$ serum samples with the new combined HPLC method and the reference ID-GC-MS method.

method $44 \mu \mathrm{mol} / \mathrm{l}-783 \mu \mathrm{mol} / \mathrm{l}$ ) $\mathrm{C}_{\text {uric acid (combined method) }}$ $=1.011 \times \mathrm{C}_{\text {uric acid (reference ID-GC-MS) }}-0.280 \mu \mathrm{mol} / \mathrm{l}$

confidence interval

for slope $b$ :

confidence interval

for intercept a: $\quad-1.31 \mu \mathrm{mol} / 1-+0.72 \mu \mathrm{mol} / \mathrm{l}$

coefficient of

correlation $\mathrm{r}$ :

1.000

The statistics for the deviations between the results ob-
Tab. 4 Summary of the data for the calculated deviations between the presented combined method for the simultanous determination of creatinine and uric acid and the chosen reference methods

\begin{tabular}{lll}
\hline & $\begin{array}{l}\text { Fraction of } \\
\text { samples }\end{array}$ & $\begin{array}{l}\text { Deviation } \\
\text { between } \\
\text { methods }\end{array}$ \\
\hline Determination of creatinine & $96 \%$ & $\leq 3.6 \%$ \\
& $62 \%$ & $\leq 2.0 \%$ \\
Determination of uric acid & $29 \%$ & $\leq 1.0 \%$ \\
& $98 \%$ & $\leq 2.5 \%$ \\
& $47 \%$ & $\leq 1.0 \%$ \\
\hline
\end{tabular}

tained with the combined method and the reference methods are summarized in table 4.

\section{Conclusions}

The aim of this study was the evaluation of a high-performance liquid chromatography for the simultaneous determination of creatinine and uric acid in serum. The imprecision was less or equal than $1.1 \%$ for both analytes, and it was below $1 \%$ for control material; the inaccuracy in the standard recovery experiments was even lower. The imprecision data from the triplicate chromatographies of the samples suggest that only one measurement of each serum dilution for all samples is required. The method was tested against a reference method for the determination of creatinine (7) and a candidate reference method for the determination of uric acid (1). For $\mathrm{n}=55$ human serum samples we found very good correlations between the results for both analytes obtained with the combined method and the methods choosen as reference. Ninety-six percent of the samples had a difference of the analytical results for creatinine between the method presented and the ID-GC-MSmethod less than or equal to $3.6 \%$. In the case of uric acid, $98 \%$ of the samples showed a difference less than or equal to $2.5 \%$. For uric acid the results are comparable to those for control materials and in the case of creatinine it is expected that due to the simpler matrix of those control materials the observable deviations should be even less than those found for patient samples.

Recently, several methods for the determinations of creatinine have been published, mostly based on cationexchange-HPLC $(8-11)$. Rosano et al. proposed a method based on this principle as a reference method (12) and Linnet et al. proposed a candidate reference method where a sample preparation procedure with cation-exchange chromatography is followed by reversedphase-HPLC and enzymatical quantification (13). The principle of ion-pair-gradient HPLC of serum-ultrafiltrates has also been utilized for the development of can= didate reference methods (14). ' 
For the separation of uric acid and creatinine, the most suited separation system was the ion-pair reversed-phase chromatography, where an added ionic modifier, in this method octanesulphonic acid, will react under certain conditions with cationic serum components to yield ionpairs, which will retard the elution by a reversed-phase stationary phase. This principle has been previously used for the HPLC of creatinine, but all methods described may introduce additional sources of imprecision and inaccuracy due to their complex sample preparation; a direct injection of a diluted and filtered serum or control material can minimize these analytical problems. The data obtained for day-to-day imprecisions as well as those for the recoveries show the advantage of the method presented here. Moreover the method evaluated in this study does not require a pump with gradient capabilities, the system only needs to be equipped with an eluent switching device, and further only a one-wavelength-tuneable UV-detector with wavelength switching is needed as the simultaneous acquisition at $232 \mathrm{~nm}$ and $292 \mathrm{~nm}$ is not absolutely required.

The method was primarily developed for clinical purposes. Here the determination of creatinine is a crucial element of patient surveillance, for example following transplantation surgery, where the drug-treat- ment of the transplanted patients is most complex and metabolism and pharmacokinetics are often in disorder. In those cases the spectrophotometrical determination of creatinine, fully enzymatic or special modifications of the Jaffé-method do not fit the requirements due to the often overly complex interferences occuring in the samples of these patients. The HPLC-method presented will therefore be of value as an "in lab reference" for the precise monitoring of the serum-concentration of creatinine and uric acid in those cases where the classical methods are suspected of giving erroneous results and the determination of these analytes is critical for the treatment of the patient.

The method presented here is the first high-performance-liquid-chromatography for the simultaneous determination of creatinine and uric acid, where a full method evaluation including a method comparison against established candidate reference method was performed. The method can be applied in clinical cases where spectrophotometric methods, which are more unspecific and more susceptible to interferences, have to be replaced. Clinical investigations concerned with this field are in progress and the applicability of the method for urine is under study.

\section{References}

1. Kock R, Delvoux B, Tillmanns U, Greiling H. A candidate reference method for the determination of uric acid in serum based on high performance liquid chromatography with an isotope dilution-gas chromatography-mass spectrometer method. J Clin Chem Clin Biochem 1989; 27:157-62.

2. Narayanan S, Appleton HD. Creatinine: a review. Clin Chem 1980; 26:1119-26.

3. Wahlefeld AW, Siedel J. Creatine and Craetinine. In: Bergmeyer $\mathrm{HU}$, editor. Methods of enzymatic analysis. Weinheim: $\mathrm{VCH}, 1875 ; 3: 488-506$.

4. Guder WG, Hoffmann GE, Hubbuch A, Poppe WA, Siedel J, Price CP. Multicentre evaluation of an enzymatic method for creatinine determination using a sensitive colour reagent. $J$ Clin Chem Clin Biochem 1986; 24:889-902.

5. Spencer K. Analytical reviews in clinical biochemistry: the estimation of creatinine. Ann Clin Biochem 1986; 23:1-25.

6. Siekmann L, Breuer H. Determination of cortisol in human plasma by isotope dilution-mass spectrometry. J Clin Chem Clin Biochem 1982; 20:883-92.

7. Siekmann L. Determination of creatinine in human serum by isotope dilution-mass spectrometry. Definitive methods in clinical chemistry IV. J Clin Chem Clin Biochem 1985; 23:137-44.

8. Ambrose RT, Ketchum DF, Smith JW. Creatinine determined by high-performance liquid chromatography. Clin Chem 1983; 29:256-9.

9. Harmoinen A, Sillankee P, Jolela H. Determination of creatinine in serum and urine by cation-exchange high-pressure liquid chromatography. Clin Chem 1991; 37:563-5.

10. Scott PH. High-performance liquid-chromatographic measurement of plasma creatinine in newborns. Clin Chem 1992; 28:101-3.

11. Xue GP, Fishlock RC, Snoswell AM. Determination of creatinine in whole blood, plasma and urine by high-performance liquid chromatography. Anal Biochem 1988; 171:135-40.

12. Rosano TG, Ambrose RT, Wu AHB, Swift TA, Yadegari P. Candidate reference method for determining creatinine in serum: method development and interlaboratory validation. Clin Chem 1990; 36:1951-5.

13. Linnet $K$, Brunnshuns I. HPLC with enzymatic detection as a candidate reference method for serum creatinine. Clin Chem $1991 ; 37: 1669-75$.

14. Schumann G, Büttner J. A candidate reference method for creatinine by HPLC. Fresenius Z Anal Chem 1986; 324:278-9.

Dr. R. Kock
Institute of Clinical Chemistry
and Pathobiochemistry
Medical Faculty
University of Technology Aachen
Pauwelsstraße 30
D-52074 Aachen
Germany


5 